Review/Meta-analyses

\title{
Subjective response to antipsychotics in bipolar disorders: A review of a neglected area
}

\author{
S.A. Strejilevich ${ }^{\mathrm{a}, *}$, S. Camino ${ }^{\mathrm{a}}$, P. Caravotta ${ }^{\mathrm{a}}$, M. Valerio ${ }^{\mathrm{a}, \mathrm{b}}$, A. Godoy $^{\mathrm{a}}$, \\ C. Gordon ${ }^{\mathrm{a}}$, M.R. Goldfarb ${ }^{\mathrm{a}}$ \\ a ÁREA, Assistance and Research in Affective Disorders, Buenos Aires, Argentina \\ ${ }^{\mathrm{b}}$ National Council of Scientific and Technical Research (CONICET), Argentina
}

\section{A R T I C L E I N F O}

\section{Article history:}

Received 23 July 2019

Received in revised form 7 September 2019

Accepted 7 September 2019

Available online 13 September 2019

\section{Keywords:}

Bipolar disorder

Antipsychotics

Subjective response

Drug attitude inventory

\begin{abstract}
A B S T R A C T
Background: The term "subjective response to antipsychotic" (SRA) refers to changes in the subjective state experienced due to antipsychotic (AP) exposition that is independent of the therapeutic or physical side effects of these drugs. This dimension of analysis has been extensively explored in schizophrenic disorders, finding that negative SRA is an early and independent predictor of compliance as well as a successful pathway to construct current theoretical frameworks of these disorders. There is an increasing use of AP in bipolar disorders' treatment (BD) but no reviews on the topic have been published to date in this population. The aim of this work is to review published data of SRA in BD patients and to discuss their clinical and theoretical implications.

Methods: An extensive search in online databases was performed. Reports were reviewed and included if they described SRA in BD or included instruments aimed to assess it. Reports of cognitive, sexual, motor autonomic side effects were excluded. Findings were summarized in a narrative fashion.

Results: Nine reports fulfilled the inclusion criteria and were included in the revision, reporting data from 1282 BD patients. Among these, three were prospective studies and three explored relations between SRA and treatment compliance.

Conclusions: There is an asymmetry between the increase in the use of antipsychotics in BD and the lack of data regarding the SRA. Phenomenologically, SRA in BD is similar to that found in schizophrenic subjects. Some of these symptoms may be misdiagnosed as depressive symptoms. The existing data show that SRA has a strong correlation with treatment compliance as well as a promising way to develop theoretical paradigms for these disorders.
\end{abstract}

(c) 2019 Elsevier Masson SAS. All rights reserved.

\section{Introduction}

The term "subjective response to antipsychotic treatment" (SRA) refers to changes in the subjective state experienced due to antipsychotic (AP) exposition of which are independent of the therapeutic or physical side effects of these drugs. In other words, it refers to how an individual "feels and considers the effect of these drugs" independently of whether or not they work in regard to alleviating the psychic symptoms for which they were indicated [25]. The development of this dimension of analysis in psychiatry started in parallel with early experiences with chlorpromazine psychiatric treatment in the $50^{\prime} \mathrm{s}[14,28]$. It was started by a generation of psychiatrists, trained in psychodynamic paradigms,

\footnotetext{
* Corresponding author at: Juncal 2061 PB C (1114), C.A.B.A., Argentina. E-mail address: sstreji@gmail.com (S.A. Strejilevich).
}

who were particularly interested in patients' narrative about their experience with these new treatments [2,16,44,57].

SRA can be characterized as positive/non-dysphoric or negative/ dysphoric according to the experience of the subjects exposed to these drugs [52]. When the SRA is positive, exposed subjects report a pleasant internal experience in which the beneficial effects of these drugs are predominant. Instead, negative/ dysphoric SRA (NSRA) refers to a pleomorphic subjective experience in which emotional detachment or restriction, indifference, loss of creativity, mental slowing, anxiety, inner restlessness, and dysphoria, among others, predominate $[2,9,16,57]$. Patients usually describe NSRA with phrases such as: "zombie-like states", "feelings of being generally unwell", "mental fogginess", "inner anxiety", "feelings of apathy", "emotional flattening", and the "inability to think clearly", etc. [36]. The experiences resulting from the exposure to antipsychotics in healthy volunteers or in people affected by other neuropsychiatric conditions have shown that NSRA is independent 
of suffering psychotic disorders [1,9,10]. As an example, two psychiatrists reported their internal experiences after self-injecting a 5-mg infusion of haloperidol: "within ten minutes a marked slowing of thinking and movement developed, along with a profound inner restlessness ( . . . )."Each subject complained of paralysis of volition and lack of physical and psychic energy. "There was no sleepiness or sedation (and) both subjects complained of severe anxiety" [7].

On subjects treated for schizophrenic disorders, NSRA would be frequent [5,21] and would not correlate with intensity of psychopathological symptoms nor with presence or intensity of the general physical side effects of the AP. Furthermore, NSRA would correlate with extrapyramidal side effects, especially with subjective akathisia $[21,22,39,52]$ and is usually experienced as more distressing than the AP physical side effects [2,36]. Over the years, NSRA has been referred to many different ways throughout the literature, such as "behavioral toxicity" [15], "dysphoric subjective response" [45,52]; "akinetic depression," or "neuroleptic-induced deficit syndrome" [30].

Between the $70^{\prime}$ s and $90^{\prime}$ s, clinical instruments to measure SRA were developed, proving to be useful in clinical, pharmacological and dynamic imaging research [42]. Among them, the most commonly used is the Drug Attitude Inventory (DAI), a 30-item self-report instrument [22]. Total score ranges from -10 to 10 , with higher scores indicating a more positive attitude towards medication. Following a discriminant analysis, a second 10 -item version (DAI-10) composed of solely SRA items was developed. The DAI has shown to have excellent reliability and validity [24] and its scores are relatively unaffected by psychiatric symptom severity [43]. DAI scores correlate significantly with level of adherence to pharmacological treatment [2]. Another frequently used scale for assessing SRA in neuroimaging studies is the "Subjective WellBeing Under Neuroleptics Scale" (SWN-K). It is a 38-item, selfreport instrument that assesses through 6-point Likert-type responses the subjective experience over the preceding seven days $[39,13]$. The SRA construct internal validity was determined by comparing the Drug Attitude Inventory and the structured interview used by Van Putten and May in their pioneer works [24].

The SRA study and assessment have been very relevant both for clinical practice and theory development. Clinically, there is robust evidence that SRA is a strong predictor of treatment compliance, overall outcome, and quality of life in subjects with schizophrenia. Early in the $70^{\prime}$ s, in a series of seminal studies, van Putten and colleagues demonstrated that very early negative/dysphoric subjective responses to AP exposition predicted adherence to treatment as well as general outcome independently of their efficacy in the control of psychiatric symptoms [51,53,54]. These findings were replicated in other studies extending the correlation of SRA to quality of life and general outcome [3,23,31,39,41,55]. The Clinical Antipsychotic Trials of Intervention Effectiveness study (CATIE) found a significant relation between DAI-10 scores and community functioning [35]. SRA assessment has also been used to explore differences between "older" and second-generation AP. While some studies indicated that schizophrenic patients on second-generation AP reported better SRA than patients clinically stabilized on older AP drugs $[4,19,38,41,56]$ others did not $[17,25]$.

On the other hand, the exploration of the subjective experiences under antipsychotics has been central to achieving a better understanding of the pathophysiology of schizophrenic syndrome as well as of the mechanism of action of these drugs. A series of studies combined subjective data with neuroimaging techniques in healthy volunteers and schizophrenic subjects. They found that the SRA is directly related to the level of occupation of D2 receptors by AP in the nigrostriatal area, independently of the production of extrapyramidal symptoms or the clinical efficacy of these drugs $[8,11,12,26,34,55]$. Specifically, using single photon emission computed tomography (SPECT), de Haan et al. concluded that
60-70\% D2 occupancy was associated with optimal subjective experience measured by the SWN-K, a similar intensity of D2 blockade that is considered optimal to produce antipsychotic effect but lower than necessary to produce extrapyramidal symptoms [11]. Finally, Kapur [27] integrated these inputs developing the currently most influential and comprehensive framework for schizophrenia. From early observations, it was evident that the therapeutic effect of AP was different from a simple extinction of psychotic symptoms [57]. For example, Elkes and Elkes [16] stated that " .. p patients [under AP] continue to be subject to delusions and hallucinations, although they appear to be less disturbed by them". Kapur's hypothesis is based on the concept that antipsychotics would not extinguish the aberrant saliences (psychotic symptoms) produced by the imbalance in the dopamine turnover. The effect of these drugs would be to diminish the emotional response to aberrant saliences and, therefore, their cognitive and behavioral impact. This theoretical framework has a twofold advantage: it links the neurochemical effects of PA with its psychologicalbehavioral manifestations, and it explains the ability of these drugs to produce an affective restriction /apathy.

Although SRA in schizophrenia remains a construct generally overlooked in clinical practice [40], its corpus of data and its impact in schizophrenia treatment and research is considerable. On the other hand, in the last years, the use of AP in bipolar disorders treatment has experienced a significant and continuous increment [32]. However, a comparable description of the subjective/psychological effects of these drugs in this population as well as a conceptual framework linking their neurochemical action to their therapeutic effects at a psychological level is lacking $[47,48]$. Therefore, the aim of this paper is to review the published literature about SRA in bipolar subjects. Its clinical and theoretical implications will be discussed.

\section{Methods}

For the purpose of the current review, all kind of reports documenting the presence ASR in bipolar disorder patients were considered. Online databases (MEDLINE, SCOPUS, EMBASE and ClinicalTrials.gov) were searched using the following terms: "BIPOLAR DISORDERS" or "ANTIPSYCHOTIC" or "NEUROLEPTICS" cross referenced with "SUBJECTIVE RESPONSE" or "TOLERABILITY" or "APATHY" or "EMOTIONAL NUMBING" or "DRUG ATTITUDE INVENTORY" or "DAI-10" or "NEUROLEPTIC INDUCED DEFICIT SYNDROME" or "SUBJECTIVE WELL-BEING UNDER NEUROLEPTICS SCALE" or "SWN-K". The term "NEUROLEPTIC INDUCED DEFICIT SYNDROME" (NIDS) was included because although it refers to negative symptoms' syndrome due to AP, the syndrome contains phenomena that are usually part of SRA descriptions (19).

Search parameters were restricted to reports published in English up to November 2018. The reference list of the articles selected for inclusion were also searched for relevant reports. With the objective to focus on SRA, information on behavioral (decision making, hypersexuality, etc), neurocognitive (attention, memory, processing speed, etc.), motor (akathisia, parkinsonism, etc.), and autonomic (erectile dysfunction, ejaculatory delay, anorgasmia, etc.) adverse events were excluded. Side effects on vigilance and appetite regulation were not considered. Findings were summarized in a narrative fashion.

\section{Results}

The search strategy resulted in a total of 9 articles that met the inclusion criteria and were thus included in this review, informing data from a total of $1282 \mathrm{BD}$ subjects. Four reports included only BD subjects $(6,46,49,50)$, three explored compliance $(6,33,49)$ and only three had a prospective design $(6,29,49)$. Given the nature of 
the found data, it was not possible to perform a quantitative analysis. To facilitate reading, the reviewed studies were grouped into thematically related categories. In addition, the relevant information about the studies' aims and methodology was extracted from each article and summarized in Table 1.

\subsection{AP Subjective Response description in bipolar disorders patients}

Moncrieff et al. [36] examined data from an Internet site (http:// www.askapatient.com), conducting qualitative and quantitative analyses of comments about the subjective experiences associated with taking olanzapine, risperidone and older neuroleptics. They included data from 439 reports of which 139 came from users who had reported having a bipolar disorder (BD) diagnosis, although a diagnostic subgroup analysis was not performed. They found that all drugs examined in this report induced similar emotional effects: feelings of flattened or numbed emotions, loss of interest and motivation, reduced creativity and perceived changes in personality. These symptoms were the most frequently reported adverse effects of these drugs along with sedation.

Moritz et al. [37] conducted an online survey in which psychotic ( $\mathrm{n}=69 ; 3$ with BD diagnosis) and nonpsychotic patients $(\mathrm{N}=26)$ taking AP were inquired about the emotional and cognitive effects of these drugs. The survey used the Effect of Antipsychotic Medication on Emotion and Cognition questionnaire (EAMEC), which contains 49 items on the subjective effects of AP. They found that, without differences between psychotic and non-psychotic subjects exposed to AP, the predominant subjective effects elicited by all AP were sedation, cognitive impairment and emotional flattening or indifference.

Ueda et al. [50] reported a series of three clinical vignettes on which neuroleptic deficit syndrome (NIDS) was superimposed with a depressive episode in BD patients treated with secondgeneration AP. In these cases, the NIDS included apathy, lack of initiative, emotional blunting, indifference and, more interestingly, poor insight into disease with a reduced desire to improve.
The drugs used in the treatment of these patients were olanzapine, risperidone, haloperidol and blonanserin. All cases improved after AP withdrawal and in some cases, after receiving electroconvulsive therapy. Authors emphasized that the previous failure to recognize NIDS in these patients produced misdiagnoses (e.g. one of them received a fronto-temporal dementia diagnosis), preventing patients from receiving effective treatment and achieving remission. In a survey administered to 100 bipolar disorder euthymic outpatients in three health care centers in Argentina, patients were asked to select the medication they had received for the $\mathrm{BD}$ treatment that generated the best or worst memories. Haloperidol was most frequently identified as the drug related to worst memories while lithium as the drug associated with the best ones [46].

Lambert et al. [29] examined the effect of diagnosis, mood state, and anxiety on subjective wellbeing in patients with diagnosis of schizophrenia spectrum $(\mathrm{N}=1681)$, schizo-affective disorder $(\mathrm{N}=249)$ and $\mathrm{BD}(\mathrm{N}=245)$, all treated with quetiapine. The sample was followed for 42 weeks after initiating or being switched to quetiapine, assessing clinical symptomatology with the Clinical Global Impression-Severity of Illness Scale (CGI-S) and subjective well-being with the Neuroleptic Treatment Scale (SWN-K). The initial score on the SWN-K scale was higher for patients with a diagnosis of bipolar disorder compared to those diagnosed with schizophrenia and schizoaffective disorder. These baseline subjective well-being differences were further explored, finding that mood status was highly associated with subjective well-being at baseline in bipolar and schizoaffective disorder, with high SWN-K scores in manic subjects (82 points) compared to depressed (56.1 points) and euthymic ones (64.8 points). In fact, mood status explained $24 \%$ of the SWN-K total score variance at baseline in affective psychoses. Finally, although all diagnostic groups reported highest scores of SWN-K (better SRA) throughout follow-up, bipolar patients' well-being improved less than that of the schizophrenics and schizo-affective disorders patients.

Table 1

Summary of relevant data about Subjective Response to Antipsychotics in BD subjects.

\begin{tabular}{|c|c|c|c|c|}
\hline Reference & $\begin{array}{l}\text { Methodology (Instruments } \\
\text { used) }\end{array}$ & Population & Kind of Data; Main findings & Drugs Involved \\
\hline Elkes \& Elkes, 1954 [16] & $\begin{array}{l}\text { Blind, case control systematic } \\
\text { observation }\end{array}$ & $\begin{array}{l}11 \text { Agitated affective } \\
\text { patients }\end{array}$ & $\begin{array}{l}\text { Narrative description of AP } \\
\text { psychological effect. }\end{array}$ & chlorpromazine \\
\hline $\begin{array}{l}\text { Strejilevich \& García Bonetto, } \\
\quad 2003 \text { [46] }\end{array}$ & $\begin{array}{l}\text { Survey of three Health } \\
\text { Care Centers }\end{array}$ & $\begin{array}{l}100 \text { BD euthymic } \\
\text { outpatients }\end{array}$ & $\begin{array}{l}\text { Haloperidol was related to worse } \\
\text { memories, lithium to best ones. }\end{array}$ & $\begin{array}{l}\text { lithium, valproate, } \\
\text { typical antipsychotics }\end{array}$ \\
\hline Moncrieff et al 2009 [36] & $\begin{array}{l}\text { Qualitative and Quantitative } \\
\text { analysis of internet database }\end{array}$ & 139 BD patients & $\begin{array}{l}\text { User comments; Flattened emotions, } \\
\text { loss of interest and motivation, reduced } \\
\text { creativity, changes in personality. }\end{array}$ & $\begin{array}{l}\text { olanzapine, risperidone, } \\
\text { typical antipsychotics }\end{array}$ \\
\hline Lambert et al., 2009 [29] & $\begin{array}{l}\text { Observational, prospective } \\
\text { (SWN-K) }\end{array}$ & 245 BD patients & Mood influence, SWN score. & Quetiapine \\
\hline Teter et al, 2011 [49] & $\begin{array}{l}\text { Observational, prospective, } \\
\text { (DAI - 10) }\end{array}$ & $\begin{array}{l}54 \text { BD inpatients with } \\
\text { and without SUD }\end{array}$ & $\begin{array}{l}\text { Adherent patients presented a higher } \\
\text { mean DAI score, regardless of the } \\
\text { presence of SUD. }\end{array}$ & $\begin{array}{l}\text { Lithium, Valproate, } \\
\text { Risperidone, Olanzapine, } \\
\text { Lorazepam }\end{array}$ \\
\hline Medina et al., 2012 [33] & Cross sectional, (DAI-10) & $\begin{array}{l}41 \text { manic patients at } \\
\text { discharge }{ }^{w} />7 \text { days } \\
\text { under AP }\end{array}$ & $\begin{array}{l}14,6 \% \text { w/ NA to AP. NA correlate } \mathrm{w} / \text { less } \\
\text { insight and stability. }\end{array}$ & Not provided \\
\hline Barraco et al., 2012 [6] & $\begin{array}{l}\text { Multicenter, observational, } \\
\text { cohort prospective (DAI-30) }\end{array}$ & $\begin{array}{l}686 \text { Bipolar I \& II } \\
\text { patients }\end{array}$ & $\begin{array}{l}\text { Negative attitude toward medication } \\
\text { was a predictor of non-adherence }\end{array}$ & $\begin{array}{l}\text { Lithium, antipsychotics, } \\
\text { antidepressants, other } \\
\text { mood stabilizers }\end{array}$ \\
\hline Moritz et al, 2013 [37] & Online Survey, (EAMEC) & 3 psychotic BD patients & $\begin{array}{l}\text { Sedation, cognitive impairment and } \\
\text { emotional flattening due to AP. Non } \\
\text { difference between psychotic and non } \\
\text { psychotic }\end{array}$ & Not provided \\
\hline Ueda et al., 2016 [50] & Clinical vignettes & 3 cases BD depression & NIDS could overlap ${ }^{\mathrm{w}} /$ depression & $\begin{array}{l}\text { Haloperidol, Risperidone. } \\
\text { Olanzapine, Blonanserin }\end{array}$ \\
\hline
\end{tabular}

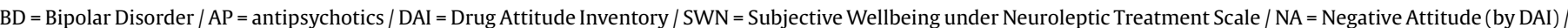
SUD = Substance Use Disorder/ EAMEC = Effect of Antipsychotic Medication on Emotion and Cognition Questionnaire/ NIDS = Neuroleptic induced deficit syndrome. 


\subsection{SRA and treatment compliance in $B D$}

Medina et al. [33], used DAI-10 in a sample of 41 BD and 45 schizophrenic subjects with good responses to treatment with AP. NSRA were reported by $40.6 \%$ of the sample. NSRA correlated with a negative perception of the disease and a high number of previous episodes, finding that the difference in the previous period of stability between those who reported NSRA and those who did not was 2.9 years $(p=0.0012)$. The DAI-10 score does not correlate with the intensity of other side effects evaluated by the Undersogelser Side Effects Rating Scale (UKU).

The Evaluation of Pharmacotherapy Adherence in Bipolar Disorder (EPHAR) is a large, prospective, multicenter, observational study in which a representative sample of 686 bipolar I \& II patients were screened to explore pharmacological treatment adherence [6]. In this study, DAI-30 version was used among other clinical parameters. A negative attitude towards medication, assessed by the DAI-30, was found among the best predictors of non-adherence, together with alcohol consumption, severity of symptoms and younger age at first episode.

In a sample of 54 bipolar disorder inpatients, Teter et al. [49] explored the impact of substance abuse disorder on pharmacological treatment adherence using the DAI-10. They found that, regardless of the presence of substance abuse, adherent patients demonstrated a statistically significantly higher mean DAI score as compared to medication non-adherent patients $(+5.3 \pm 4.4$ vs. $0.25 \pm 6.4 ; \mathrm{p}<0.001)$. Additionally, DAI scores were lower in inpatients that suffered substance abuse at the moment of the study.

\subsection{Insights into physiopathology of bipolar disorders from SRA data}

In a study about the behavioral effect of chlorpromazine in agitated patients (11 of these with mood disorders), the researchers reported that despite the fact of a general improvement in chronic agitation, "those patients who suffered from recurrent attacks of hypomania became less excitable and aggressive during the phases, though their affective swings continued at intervals normal to each patient. The chronically agitated melancholic, while becoming less tense and at times apparently less miserable, did not themselves admit to any improvement in their mental state" [16]. Belmaker and Wald [7], at the time of discussing their experiences under haloperidol, highlighted that: "The similarity of the abovedescribed state to that of some cases of agitated depression and postpsychotic depression suggests involvement of dopamine in these affective states". Taking into account this early report, Strejilevich et al. [47] reviewed subjective experiences in situations of sudden dopamine depletion, including data from on-off effects in Parkinson's disease in L-Dopa treatment. The similarity between descriptions about inner experiences under sudden dopamine depletion with clinical descriptions of depressive mixed states led these authors to propose a physiological model for mixed states.

\section{Discussion}

The main result of this review is that, compared to schizophrenic disorders, there is a notable lack of data and consideration about SRA in BD. However, the minimal existing data on SRA in BD patients support the potential interest that this dimension of analysis should take for clinical and theoretical research of bipolar disorders.

Phenomenologically, NSRA in people affected by BD seems to be similar to that reported by people suffering from schizophrenia and by healthy subjects. The limited data does not allow to infer the incidence in this population. However, if we take into account the positive correlation between NSRA and akathisia and other extrapyramidal symptoms, It is plausible to hypothesize that NSRA could be even more frequent in BD subjects considering that they are twice as sensitive to the mentioned motor side effects than their schizophrenic counterparts [18].

In the few studies in which this correlation was tested, SRA has shown to have a strong correlation with adherence to pharmacological treatment in BD. The correlation between NSRA and treatment compliance was independent of other pharmacological side effects, drug or alcohol abuse, and the severity of symptoms. However, unlike in schizophrenic subjects, SRA measures in BD patients could be influenced by the mood fluctuations of these disorders. In the only study in which SRA was prospectively explored, the presence of manic symptoms seemed to attenuate the NSRA responses.

The lack of information about SRA in BD is especially regrettable considering the insights that this dimension of analysis could offer about the pathophysiology of these disorders and the mechanisms of action of different drugs used for treatment of BD. As opposed to AP for schizophrenia [27] and antidepressants for non-bipolar depression treatment [20], in the case of BD there is no theoretical framework that links the effect of pharmacological treatment at a biochemical-neuroplastic level with their effects at a psychological level. In fact, leaving aside the hypothesis proposed about mixed states based in dopamine depletion experiences [47], we did not find other proposals in this line. Taking into account the increasing use of AP in BD maintenance treatment, it is crucial to fill this gap. With the limited data currently available, it is possible to hypothesize that the efficacy of AP on delaying the appearance of new episodes could be related to their ability to produce a restriction of emotional response (apathy) but not a direct effect over the mechanisms that regulate normal mood fluctuations. These hypothetical differences in the mechanism of action of AP in the maintenance treatment of BD could be relevant, since apathy would produce significant functional detriments [58]. The incorporation of apathy and SRA scales in the trials that test AP, especially in those that compare them with lithium, would be a simple yet important step to address this problem.

In the same way, there is currently a gap between the knowledge of AP mechanisms at the cellular level with their effect at a clinical level in BD. Given the key contribution that knowledge about the subjective effects of pharmacological treatment has had on the formulation of this type of

hypotheses in major depression and schizophrenia, it is possible that a greater understanding of this dimension of analysis could help settle this important debt in BD.

In summary, in the context of an increasing use of antipsychotics in bipolar disorders treatment, there is a striking lack of data about the subjective impact of these drugs in this population. However, the few available data show that this cluster of analysis could be a strong and independent predictor of treatment compliance and general outcome. Furthermore, inputs from SRA could help develop a theoretical framework able to link the biochemical effects of antipsychotics with their specific effects at a psychopathological/behavioral level in bipolar disorders.

\section{References}

[1] Artaloytia JF, Arango C, Lahti A, et al. Negative signs and symptoms secondary to antipsychotics: a double-blind, randomized trial of a single dose of placebo, haloperidol, and risperidone in healthy volunteers. Am J Psychiatry 2006;163 (3):488-93.

[2] Awad A. Subjective response to neuroleptics in schizophrenia. Schizophr Bull 1993;19(3):609-18.

[3] Awad AG, Hogan TP, Voruganti LN, et al. Patients' subjective experiences on antipsychotic medications: implications for outcome and quality of life. Int Clin Psychopharmacol 1995;10(September (Suppl 3)):123-32. 
[4] Awad AG, Voruganti LN. New antipsychotics, compliance, quality of life, and subjective tolerability - are patients better off? Can J Psychiatry 2004;49 (5):297-302.

[5] Barbui C, Nosè M, Bindman J, et al. Sex differences in the subjective tolerability of antipsychotic drugs. J Clin Psychopharmacol 2005;25(6):521-6.

[6] Barraco A, Rossi A, Nicolò G, et al. Description of study population and analysis of factors influencing adherence in the observational Italian study "Evaluation of Pharmacotherapy Adherence in Bipolar Disorder" (EPHAR). CNS Neurosci Ther 2012;18(2):110-8.

[7] Belmaker RH, Wald D. Haloperidol in normals. Br J Psychiatry 1977;131:222-3.

[8] Bressan R, Costa D, Jones HM, et al. Typical antipsychotics drugs - D(2) receptor occupancy and depressive symptoms in schizophrenia. Schizophr Res 2002;56(1-2):31-6.

[9] Caine ED, Polinsky RJ. Haloperidol-induced dysphoria in patients with Tourette syndrome. Am J Psychiatry 1979;136(9):1216-12717.

[10] de Haan L, Booij J, Lavalye J, et al. Subjective experiences during dopamine depletion. Am J Psychiatry 2005;162(9):1755.

[11] de Haan L, Lavalaye J, Linszen $D$, et al. Subjective experience and striatal dopamine D2 receptor occupancy in patients with schizophrenia stabilized by olanzapine or risperidone. Am J Psychiatry 2000;157(6):1019-20.

[12] de Haan L, van Bruggen M, Lavalaye J, et al. Subjective experience and D2 receptor occupancy in patients with recent-onset schizophrenia treated with low-dose olanzapine or haloperidol: a randomized, double-blind study. Am J Psychiatry 2003;160(2):303-9.

[13] de Haan L, Weisfelt M, Dingemans PM, et al. Psychometric properties of the subjective well-being under neuroleptics scale and the subjective deficit syndrome scale. Psychopharmacol (Berl) 2002;162(1):24-8.

[14] Delay J, Deniker PHJ. Therapeutic method derived from hiberno-therapy in excitation and agitation states. Ann médico-psychologiques(París) 1952;110 (22):267-73.

[15] DiMascio A, Shader RI. Behavioral toxicity of psychotropic drugs. I. Definition. II. Toxic effects on psychomotor functions, Connect Med 1968:32(8):617-20.

[16] Elkes J, Elkes C. Effect of chlorpromazine on the behavior of chronically overactive psychotic patients. Br Med J 1954;2(4887):560-5.

[17] Franz M, Lis S, Plüddemann K, et al. Conventional versus atypical neuroleptics: subjective quality of life in schizophrenic patients. Br J Psychiatry 1997; 170:422-5.

[18] Gao K, Kemp DE, Ganocy SJ, et al. Antipsychotic-induced extrapyramidal side effects in bipolar disorder and schizophrenia: a systematic review. J Clin Psychopharmacol 2008;28(2):203-9.

[19] García-Cabeza I, Gómez JC, Sacristán JA, et al. Subjective response to antipsychotic treatment and compliance in schizophrenia. A naturalistic study comparing olanzapine, risperidone and haloperidol (EFESO Study). BMC Psychiatry 2001;1:7.

[20] Harmer CJ, Hill SA, Taylor MJ, et al. Toward a neuropsychological theory of antidepressant drug action: increase in positive emotional bias after potentiation of norepinephrine activity. Am J Psychiatry 2003;160(5):990-2.

[21] Hofer A, Rettenbacher MA, Edlinger M, et al. Subjective response and attitudes toward antipsychotic drug therapy during the initial treatment period: a prospective follow-up study in patients with schizophrenia. Acta Psychiatr Scand 2007;116(5):354-61.

[22] Hogan TP, Awad AG, Eastwood MR. A self-report scale predictive of drug compliance in schizophrenics: reliability and discriminative validity. Psychol Med 1983;13(1):177-83.

[23] Hogan TP, Awad AG, Eastwood MR. Early subjective response and prediction of outcome to neuroleptic drug therapy in schizophrenia. Can J Psychiatry 1985;30(4):246-8.

[24] Hogan TP, Awad AG. Subjective response to neuroleptics and outcome in schizophrenia: a re-examination comparing two measures. Psychol Med 1992:22(2):347-52.

[25] Jones PB, Barnes TR, Davies L, et al. Randomized controlled trial of the effect on Quality of Life of second- vs first-generation antipsychotic drugs in schizophrenia: cost Utility of the latest Antipsychotic Drugs in Schizophrenia Study (CUtLASS 1). Arch Gen Psychiatry 2006;63(10):1079-87.

[26] Kapur S, Zipursky R, Jones C, et al. Relationship between dopamine D(2) occupancy, clinical response, and side effects: a double-blind PET study of first- episode schizophrenia. Am J Psychiatry 2000;157(4):514-20.

[27] Kapur S. Psychosis as a state of aberrant salience: a framework linking biology, phenomenology, and pharmacology in schizophrenia. Am J Psychiatry 2003;160(1):13-23.

[28] Laborit HHP. L' hibernation artificielle par moyens pharmacodynamiques et physisques. Press médicale 1951;59(64):1329.

[29] Lambert M, Naber D, Karow A, et al. Subjective wellbeing under quetiapine treatment: effect of diagnosis, mood state, and anxiety. Schizophr Res 2009; $110(1-3): 72-9$.

[30] Lewander T. Neuroleptic and the neuroleptic-induced deficit syndrome. Acta Psychiatr Scand Suppl 1994;380:8-13.
[31] Löffler W, Kilian R, Toumi M, et al. Schizophrenic patients' subjective reasons for compliance and noncompliance with neuroleptic treatment. Pharmacopsychiatry 2003;36(3):105-12.

[32] Lyall LM, Penades N, Smith DJ. Changes in prescribing for bipolar disorder between 2009 and 2016: national-level data linkage study in Scotland. Br J Psychiatry 2019;215(1):415-21.

[33] Medina E, Salvà J, Ampudia R, et al. Short-term clinical stability and lack of insight are associated with a negative attitude towards antipsychotic treatment at discharge in patients with schizophrenia and bipolar disorder. Patient Prefer Adherence 2012;6:623-9.

[34] Mizrahi R, Rusjan P, Agid O, et al. Adverse subjective experience with antipsychotic and its relationship to striatal and extrastriatal D2 receptors: a PET study in schizophrenia. Am J Psychiatry 2007;164(4):630-7.

[35] Mohamed S, Rosenheck R, McEvoy J, et al. Cross-sectional and longitudinal relationships between insight and attitudes toward medication and clinical outcomes in chronic schizophrenia. Schizophr Bull 2009;35(2):336-46.

[36] Moncrieff J, Cohen D, Mason J. The subjective experience of taking antipsychotic medication: a content analysis of Internet data. Acta Psychiatr Scand 2009;120(2):102-11.

[37] Moritz S, Andreou C, Klingberg S, et al. Assessment of subjective cognitive and emotional effects of antipsyhotic drugs. Effect by defect? Neuropharmacology 2013;72:179-86.

[38] Naber D, Moritz S, Lambert M, et al. Improvement of schizophrenic patient's subjective well-being under atypical antipsychotic drugs. Schizophr Res 2001;50(1-2):79-88.

[39] Naber D. A self-rating to measure subjective effects of neuroleptic drugs, relationships to objective psychopathology, quality of life, compliance and other clinical variables. Int Clin Psychopharmacol 1995;10(3):133-8.

[40] Naber D. Subjective effects of antipsychotic treatment. Acta Psychiatr Scand 2005;111(2):81-3.

[41] Ritsner M, Gibel A, Perelroyzen G, et al. Quality of life outcomes of risperidone, olanzapine, and typical antipsychotics among schizophrenia patients treated in routine clinical practice: a naturalistic comparative study. J Clin Psychopharmacol 2004;24(6):582-91.

[42] Rossi A, Arduini L, Stratta P, et al. Subjective experience and subjective response to neuroleptics in schizophrenia. Compr Psychiatry 2000;41(6):4669.

[43] Sajatovic M, Rosch DS, Sivec HJ, et al. Insight into illness and attitudes toward medications among inpatients with schizophrenia. Psychiatr Serv 2002;53 (10):1319-21.

[44] Sarwer-Foner G. On the mechanism of action of neuroleptic drugs: a theoretical psycho dynamic explanation. Recent Adv Biol Psychiatry 1963;6:217-32.

[45] Singh M. Dysphoric response to neuroleptic treatment in schizophrenia and its prognostic significance. Dis Nerv Syst 1976;37(4):191-6.

[46] Strejilevich S, Garcia Bonetto G. Subjective responses to pharmacological treatments in bipolar patients. J Affect Disord 2003;77(2):191-2.

[47] Strejilevich SA, Teitelbaum J, Martino DJ, et al. Dopamine sudden depletion as a model for mixed depression. Med Hypotheses 2012;78(January (1)): $107-12$.

[48] Szmulewicz A, Samamé C, Caravotta P, et al. Behavioral and emotional adverse events of drugs frequently used in the treatment of bipolar disorders: clinical and theoretical implications. Int J Bipolar Disord 2016;4(1):6.

[49] Teter CJ, Falone AE, Bakaian AM, et al. Medication adherence and attitudes in patients with bipolar disorder and current versus past substance use disorder. Psychiatry Res 2011;190(2-3):253-8.

[50] Ueda S, Sakayori T, Omori A, et al. Neuroleptic-induced deficit syndrome in bipolar disorder with psychosis. Neuropsychatry Dis Treat. 2016;12:265-8.

[51] Van Putten T, May PR, Marder SR, et al. Subjective response to antipsychotic drugs. Arch Gen Psychiatry 1981;38(2):187-90.

[52] Van Putten T, May RP. "Akinetic depression" in schizophrenia. Arch Gen Psychiatry 1978;35(9):1101-7.

[53] Van Putten T, May RP. Subjective response as a predictor of outcome in pharmacotherapy; the consumer has a point. Arch Gen Psychiatry 1978;35 (4):477-80.

[54] Van Putten T. Why do schizophrenic patients refuse to take their drugs? Arch Gen Psychiatry 1974:31(1):672.

[55] Voruganti L, Awad AG. Neuroleptic dysphoria: towards a new synthesis. Psychopharmacol (Berl) 2004;171(2):121-32.

[56] Voruganti L, Cortese L, Oyewumi L, et al. Comparative evaluation of conventional and novel antipsychotic drugs with reference to their subjective tolerability, side-effect profile and impact on quality of life. Schizophr Res 2000;43(2-3):135-43.

[57] Winkelman N. Chlorpromazine in the treatment of neuropsychiatric disorders JAMA 1954;155(1):18-21.

[58] Yuen GS, Bhutani S, Lucas BJ, et al. Apathy in late-life depression: common, persistent, and disabling. Am J Geriatr Psychiatry 2015;23(5):488-94. 